\section{Commentary: Lateral tunnel or extracardiac conduit for a Fontan operation: Is that your final answer?}

David Barron, MD, FRCS(CT), and Alvise Guariento, MD

When Francis Fontan first performed the procedure that would bear his name, little did he know that 50 years later we would still be debating how best to do it. ${ }^{1}$ Despite the extracardiac conduit (ECC) having become the most widely practiced technique, the lateral tunnel (LT) is still commonly used. We are now faced with a growing list of large, single-institution studies and registry reports that seem to provide contradictory evidence regarding which is preferable. A recent study from Boston Children's Hospital has fueled the debate, suggesting that the LT may offer better outcomes despite the global trend toward the ECC. ${ }^{2}$

The article by Daley and d'Udekem ${ }^{3}$ is a welcome attempt to appraise the available literature to try and give us a final answer. The wealth of data look ripe for a detailed metaanalysis, but we acknowledge that it is not that simple. Indeed, it is nearly impossible to adjust for the myriad variables and missing data that confound so many of the published studies. Even more importantly, the exact pre-Fontan hemodynamic parameters vary from study to study. Data are frequently incomplete and an intrinsic confounding era effect is often present, considering the earlier development of an LT. All of these make the construction of a meaningful meta-analysis difficult, as previous authors have found. ${ }^{4}$

Knowing the problems of the failing Fontan, it makes good sense to completely exclude the atria from the Fontan circuit, thus avoiding the atrial distension that can be a

\footnotetext{
From the Division of Cardiovascular Surgery, The Labatt Family Heart Centre, The Hospital for Sick Children, University of Toronto, Toronto, Ontario, Canada. Disclosures: The authors reported no conflicts of interest.

The Journal policy requires editors and reviewers to disclose conflicts of interest and to decline handling or reviewing manuscripts for which they may have a conflict of interest. The editors and reviewers of this article have no conflicts of interest.

Received for publication Dec 22, 2020; revisions received Dec 22, 2020; accepted for publication Dec 23, 2020; available ahead of print Dec 31, 2020.

Address for reprints: David Barron, MD, FRCS(CT), Division of Cardiovascular Surgery, The Labatt Family Heart Centre, The Hospital for Sick Children, 555 University Ave, Toronto, Ontario M5G 1X8 Canada (E-mail: david.barron@ sickkids.ca). J Thorac Cardiovasc Surg 2021;162:1835-6 0022-5223/\$36.00

Crown Copyright $(\subset) 2020$ Published by Elsevier Inc. on behalf of The American Association for Thoracic Surgery

https://doi.org/10.1016/j.jtcvs.2020.12.108
}

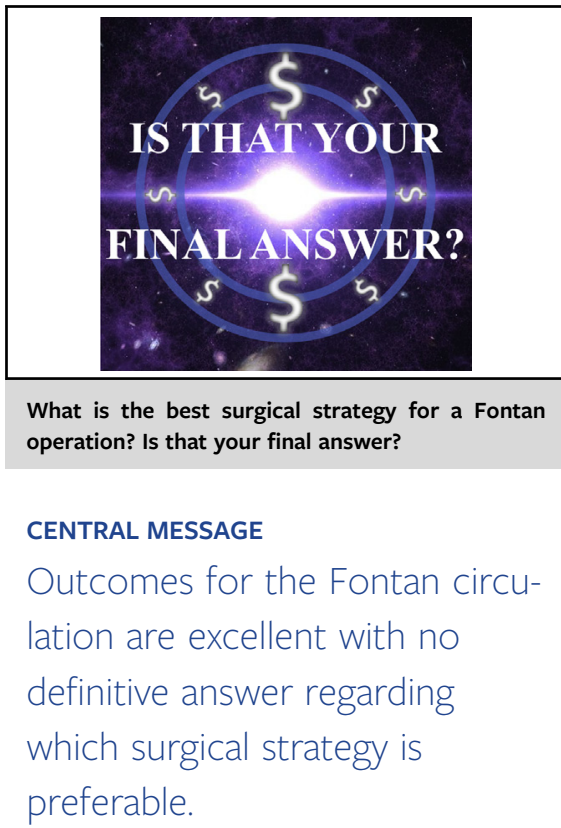

prequel to atrial arrhythmia and thrombosis. Daley and d'Udekem's analysis ${ }^{3}$ does indeed suggest that ECC may reduce these risks, but that an appropriately sized conduit must be chosen (influenced by age at Fontan). Conversely, incorporation of the right atrium into the Fontan pathway does allow some distensibility and venous capacitance,

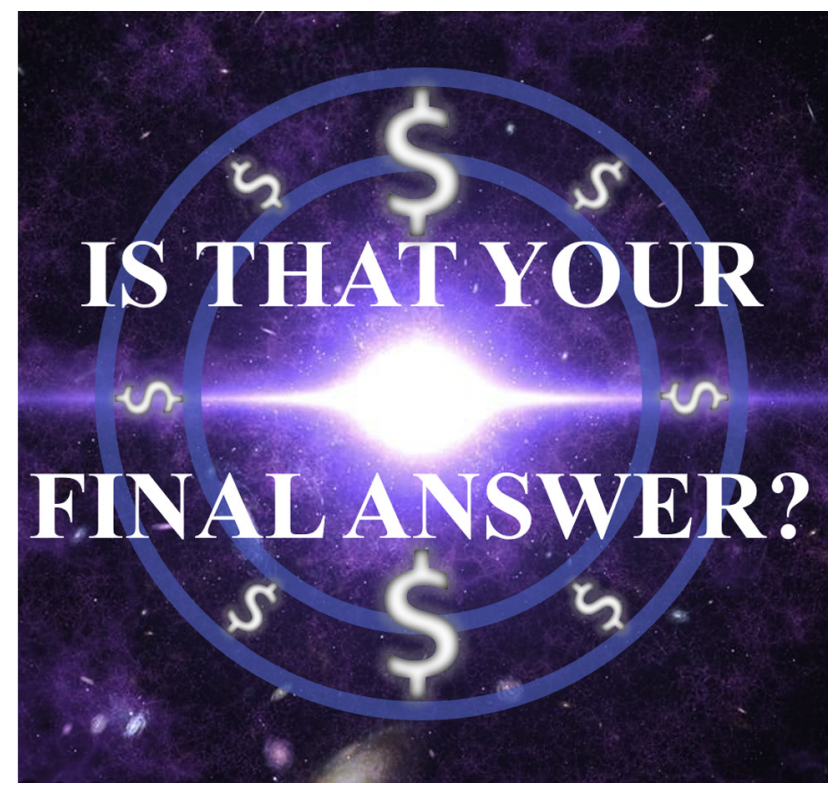

FIGURE 1. What is the best surgical strategy for a Fontan operation? Is that your final answer? 
which may explain why the LT is associated with less and shorter duration of pleural drainage.

The truth seems to be that both provide extremely effective Fontan circulations with nearly entirely equivalent outcomes. In a Fontan physiology, good ventricular function and low pulmonary vascular resistance pretty much trump anything and are likely to be far more important in dictating outcomes than the exact type of the Fontan we choose. ${ }^{5}$ The roles of fenestrations and anticoagulation regimens may also have much more relevance than LT versus ECC.

We can be reassured that both LT and ECC have excellent outcomes and, to some extent, we are free to choose what we are most comfortable with. The authors suggest a randomized clinical trial (always the ideal solution) but the reality is that there may be little appetite for this given that outcomes with both are so good. It may be that new large registries, such as the Australia and New Zealand Fontan Registry, may give us the answer.
Given the efficacy of both techniques, future interest is likely to be more focused on providing augmentation for the existing Fontan circulations, whether as mechanical or bioassisted, temporary or permanent systems. Which is better, LT or ECC? Final answer: We don't know yet (Figure 1).

\section{References}

1. Fontan F, Baudet E. Surgical repair of tricuspid atresia. Thorax. 1971;26:240-8.

2. Weixler VHM, Zurakowski D, Kheir J, Guariento A, Kaza AK, Baird CW, et al Fontan with lateral tunnel is associated with improved survival compared with extracardiac conduit. J Thorac Cardiovasc Surg. 2020;159:1480-91.e2.

3. Daley M, d'Udekem Y. The optimal Fontan operation: lateral tunnel or extracardiac conduit? J Thorac Cardiovasc Surg. 2021;162:1825-34.

4. Ben Ali W, Bouhout I, Khairy P, Bouchard D, Poirier N. Extracardiac versus lateral tunnel fontan: a meta-analysis of long-term results. Ann Thorac Surg. 2019;107:837-43.

5. Hosein RBM, Clarke AJB, McGuirk SP, Griselli M, Stumper O, De Giovanni JV, et al. Factors influencing early and late outcome following the Fontan procedure in the current era. The "Two Commandments"? Eur J Cardiothorac Surg. 2007;31: 344-53.
See Article page $\mathbf{1 8 2 5}$

\section{Commentary: The Fontan technique controversy: Where is the real equipoise?}

\author{
James K. Kirklin, MD
}

Daley and Udekem ${ }^{1}$ summarize a PubMed database search of reported outcomes comparing the lateral tunnel and extracardiac conduit (ECC) techniques for the modified Fontan operation. Following an extensive review of

\footnotetext{
From the Division of Cardiothoracic Surgery, University of Alabama at Birmingham, Birmingham, Ala.

Dr Kirklin reported partial salary paid to his institution for his role as director of the data and clinical coordinating center for the Society of Thoracic Surgeons INTERMACS (Interagency Registry for Mechanically Assisted Circulatory Support).

Disclosures: The author reported no conflicts of interest.

The Journal policy requires editors and reviewers to disclose conflicts of interest and to decline handling or reviewing manuscripts for which they may have a conflict of interest. The editors and reviewers of this article have no conflicts of interest.

Received for publication Dec 23, 2020; revisions received Dec 23, 2020; accepted for publication Dec 23, 2020; available ahead of print Jan 7, 2021.

Address for reprints: James K. Kirklin, MD, Division of Cardiothoracic Surgery, Kirklin Institute for Research in Surgical Outcomes (KIRSO), Department of Surgery, University of Alabama at Birmingham (UAB), ZRB 739, 703 19th St South, Birmingham, AL 35294 (E-mail: jkirklin@uabmc.edu).

J Thorac Cardiovasc Surg 2021;162:1836-7

0022-5223/\$36.00

Copyright (c) 2021 by The American Association for Thoracic Surgery

https://doi.org/10.1016/j.jtcvs.2020.12.121
}

Check for updates

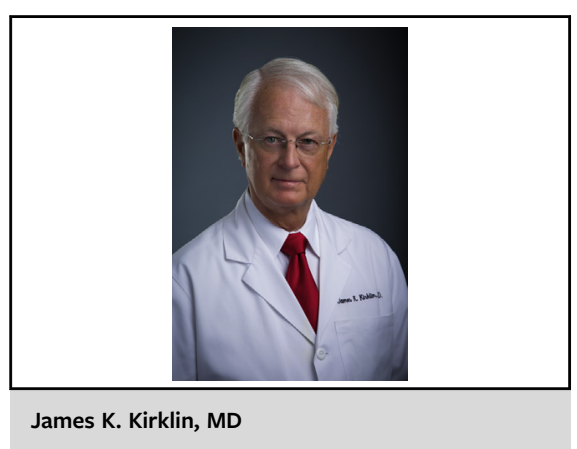

CENTRAL MESSAGE

The optimal technique for the

Fontan operation remains

elusive. Other long-term chal-

lenges of the Fontan physiology

dominate our decision-making.

pertinent publications, the authors conclude that "after almost 3 decades, there is little evidence of the superiority of one technique over the other in terms of long-term outcomes." However, a number of potential differences are discussed. In viewing this controversy, we see common themes that have played out in other areas of cardiac surgery, namely, the presumptive advantage of cardiac reconstructions using autologous tissues with the opportunity for 